\title{
A DSS design method based on organizational change
}

\author{
Claudio Ferioli \\ Dpt. of Economics and Production - Politecnico di Milano \\ P.zza Leonardo da Vinci, 32 - 20133 Milano - Italy \\ Fax +39.2.2399.2720 \\ E-Mail ferioli@mail.ecopro.polimi.it
}

\author{
Piero Migliarese \\ Università della Calabria e Politecnico di Milano \\ P.zza Leonardo da Vinci, 32 - 20133 Milano - Italy \\ Fax +39.2.2399.2720 \\ E-Mail migliare@mail.ecopro.polimi.it
}

\begin{abstract}
The paper proposes a DSS design approach based on three organizational aspects: (i) the analysis of decisional requirements of managers, (ii) the changes the DSS causes in users work habits and (iii) the changes the DSS causes in organizational power equilibrium. The aim of the proposed approach is to save the implementation from failure and to foresee reasons why organization components might reject the DSS. For each of the three aspects the paper describes the main problem the DSS designer has to face with and some solutions are proposed. In particular, as regards the analysis of power equilibrium changes, the paper proposes a new method based on the analysis of the network of relations existing in the organization. The relational method overcomes some of the limits of the two classical organizational approaches to political analysis of IT system introduction in organizations: i.e. the transaction cost perspective and the organization power theory. The paper describes an application of the proposed design approach, regarding the DSS introduction in a public health agency.
\end{abstract}

\section{Keywords}

DSS design, organizational change, network analysis, relational analysis. 


\section{INTRODUCTION: THE GAP BETWEEN DSS AND ORGANIZATIONS}

Research on DSS has been conducted for more than 15 years in the international scientific community (Angehrn and Jelassi, 1994; Gorry and Morton, 1971) and has obtained several important results, such as the development of decisional theories and software tools for individual preferences modeling, for finding single or multi-attribute functions, for decomposing such functions, etc. (Radermacher, 1994). DSS topics have been extended from individual decision support to Group decision support (GDSS) (Nunamaker, Vogel and Konsynski, 1989; Gallupe, Bastianutti and Cooper, 1991; Poole and De Sanctis, 1992; Migliarese, 1992) and to Organizational decision support (ODSS) (Lee, McCosh and Migliarese, 1988; George, Nunamaker and Valacich, 1992). Decisional support tools have been commercialized by several software houses, even if under different labels (DSS, EIS, MIS, etc)

In spite of the important theoretical results some authors underline that there is a gap between the DSS technical potentiality and their (limited) use in organizations; this gap exists for most of innovative IT application too (Ciborra, 1993). At large, Information Technologies are not playing the expected central role in organization developments and in emerging competitive changes (Land, 1995).

This gap may be explained from different points of view. It may be underlined that organizations and persons have a natural inertia. The speed of technical development is greater than that of organizational and personnel changes. Existing DSS (as well as other innovative IT applications) are useful tools for management to achieve their ends (Bariff and Ginzberg, 1982): at present they are scarcely used because of managers' psychological resistance, but they will be completely adopted in the future, when new decision makers will take the place of those who are now managing organizations.

A second perspective explains the gap through technical reasons (Radermacher, 1994; Bell, 1992). DSS are not used because they don't provide real help to decision makers. According to some authors, current decision support systems provide only low level support, based on data organization and on an enormous amount of computations of an easy but tedious nature. Instead it is necessary to design more powerful DSS that are able to support complex and sophisticated decisional processes. New technical solutions are to be discovered, for example in the field of Artificial Intelligence.

A third point of view considers mainly organizational problems (Mumford, 1979). The gap is due to a mismatching between DSS and organizations: some innovative IT applications are implemented without considering social and organizational constraints (Whitaker, 1994). A socio-technical approach is then required: DSS design should comprise also the analysis of DSS impact on organization and the introduction of a new decision tool should be coupled with planned organizational changes (Keen, 1980).

This paper proposes a design approach for managerial DSS that embraces mainly the third perspective: this choice is due only to the obvious need to set limits on the field of research.

As a matter of fact each of the three points of view may be correct for some situations and wrong for others. The designing of decision support tools should take into account suggests from the three of them. 
The proposed design approach links DSS design to the social and technical analysis of the organization. Three interdependent aspects are considered as relevant for managerial DSS design:

(1) the decisional requirements of managers,

(2) the changes the tool requires in users' work habit, that may cause resistance to the new tool introduction and even lead to its failure (work habit changes),

(3) the changes in power equilibrium of organization, that may cause a resolute opposition to the system (political changes).

In the following the paper will refer to managerial DSS requiring an "ad hoc" and continuous data entry process (i.e. following considerations are not valid for DSS that use already existing data bases, created for example for accounting purposes, customer order collection, etc.).

On one hand the design of these managerial DSS needs to satisfy the requests of managers and to provide effective help for their decision taking .

On the other hand the designers must prevent opposition to the tool by the users who are required to enter the data even if they gain no direct benefits from the tool (Grudin, 1989). Refusals may derive from unwelcome or misunderstood changes in work habits (work habits changes) as well as from the defence of the actual role and power in organization (political changes).

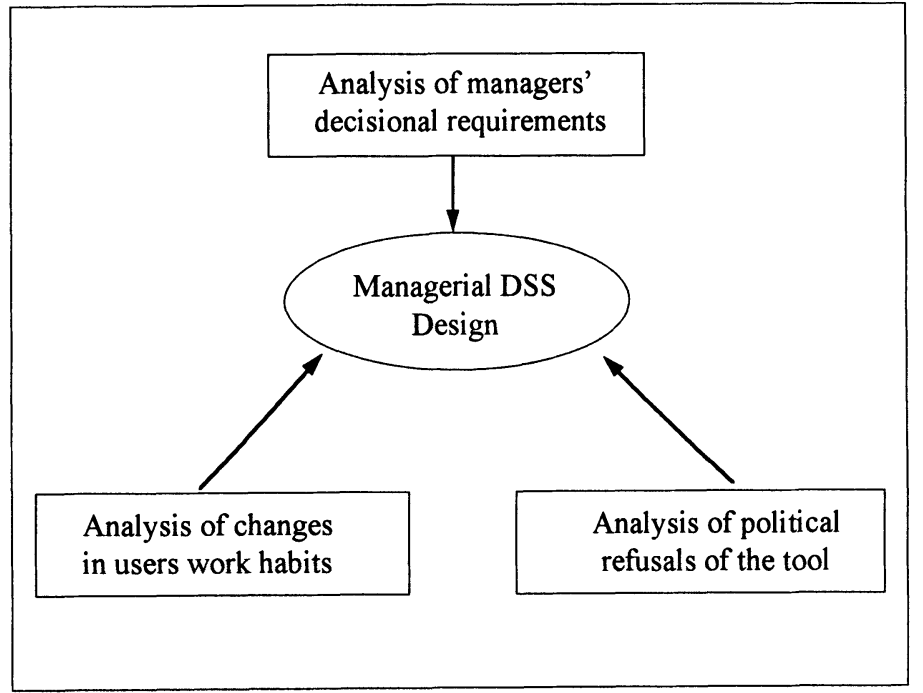

Figure 1. The proposed design approach.

The next paragraphs will examine these three aspects and will provide an approach for designing managerial DSS introduction in organizations. 
The proposed approach is partially based on existing literature, mainly as regards the analysis of manager decisional requirements (section 2) and of work habits changes (section 3 ).

For the political change problem, the paper proposes instead a new method based on the analysis of the network of relations existing in the organization (section 4.3).

Organizations are described as networks composed of nodes (individuals, groups, organizational units, etc.) linked through complex relations of several types (economic relations, hierarchical relations, interpersonal relations, etc.). The set of existing relations influences the behavior of each node towards the other ones: friendship, collaboration, competition, hostility, etc. In particular the level of opposition against a managerial DSS is due to the relations linking the managers (who will benefit from the system and decide its introduction in the organization) and the other employees, who won't receive direct benefits from the system.

This method is proposed for overcoming some of the limits of the two classical approaches in the analysis of political opposition to new technical system: the transaction costs theory (section 4.1) and the organization power perspective (section 4.2).

As an example, the paper will describe the application of the proposed designing approach in a real organization (section 5).

\section{THE ANALYSIS OF MANAGERS' REQUIREMENTS}

The first aspect considered in the design of a managerial DSS is discovering of the decision requirements of managers (Rockart, 1979).

Organizations are considered as the result of decisions taken by persons at different levels in the hierarchy. The decision maker is supposed to act in an intentionally rational way (Thompson, 1967): the problems he has to face concern limitations of the human mind and complexity of the external environment. A DSS has to facilitate the decision process and support the decision actors. This perspective is focused on the decision maker: the design of an IT tool begins with the analysis of the decision needs of the end user; the data model and the whole system are then designed in order to satisfy the discovered requirements (structured analysis) (McMenamin and Palmer, 1984).

The classical analysis of decisional requirements of managers considers problems in DSS design deriving from "intrinsic" limitations in the human decision making process (Simon, 1976). Those problems affect not only the decision processes of organizational actors but also the design of IT based support. Some of the main problems concern for example: the bounded rationality of the decision actor, the presence of uncertainty, differences in individual preferences, the tacit knowledge, the feature of adaptive rationality (Table 1).

Limits deriving from non collaboration of other organizational actors, opportunistic use of information, social impact of information technology, etc., are not taken into account (DeMarco, 1978).

The bounded rationality affects the analysis of decision requirements of managers: the human mind of design team members is unable to discover all the decision needs that a DSS has to satisfy (Hewitt and De Jong, 1984). A prototyping approach partly solves this problem, by enabling a cycle of interaction with the end user that facilitates the emerging of decision needs (Ives and Olson, 1984). 
High levels of uncertainty affect several aspects of an IT based support systems (output required, input collected, use of the system, etc.) as this may produce situations that never existed before (Ciborra, Migliarese and Romano, 1984; Heiner, 1983). The design of IT systems should realize flexible or easy-to-modify tools in order to cope with unexpected changes (Davies, 1992).

Differences in end users individual preferences are problematic mainly for multi-user support systems and for commercial (non custom) tools. A possible solution (used mainly in GDSS) regards the possibility for user preference specification; another solution (used in some commercial tools) is provided by the production of easy-to-tailor systems (Gardner, Paul and Patel, 1995).

The tacit knowledge indicates that not all knowledge is formalisable and so can be included in IT based decisional support. Parts of an individual's knowledge and an organization's knowledge are not transparent and accessible to the designer (Polany, 1966; Sternberg and Wagner, 1986) This problem enlarges the use of design techniques that are based on end-user participation in order to extract the superior knowledge of end-users (Briefs, Ciborra and Schneider, 1984).

The adaptive rationality concerns the process of individual and organizational learning (Argyris, 1982; Piaget, 1974; Weick, 1979; Norman, 1983). The expertise of DSS users increases through a learning-by-using process (Rosenberg, 1982): users get progressively more keen on DSS use and discover new possible area of application. This increasing expertise changes the decision needs: some of the old functions became superfluous and new ones are requested. Two solutions may be adopted: the first is the use of prototyping techniques for system development; the second is to implement easy-to-redesign and easy-to-upgrade systems (Mumford, 1991).

Table 1. Main problems and classical solution for the analysis of DSS user requirements

\begin{tabular}{ll}
\hline Main problems & Classical solutions \\
\hline Bounded rationality & Prototyping approach \\
\hline Uncertainty & Flexible and easy-to-modify systems \\
\hline Differences in user preferences & Possibility for preferences specification. \\
& Easy-to-tailor systems. \\
\hline Tacit knowledge & $\begin{array}{l}\text { Design techniques based on end user } \\
\text { participation }\end{array}$ \\
\hline Adaptive rationality & Prototyping approach \\
& Easy-to-upgrade and/or easy-to-redesign tools \\
\hline
\end{tabular}

According to this perspective, the designer's efforts are concentrated on the development of an IT system able to satisfy the users' decision requirements and to cope with intrinsic constraints of the human mind and of the external environment. The challenge facing the system designer is to produce the best technical solution for supporting the end users. High technical expertise is required, both in software implementation and in software engineering for providing the best decisional support and for reducing the effects of underlined problems (Table 2). 
Table 2. A synthesis of the analysis of decisional requirements of the manager.

\begin{tabular}{lll}
\hline Key actors & Considered Constraints & Role of the designer \\
\hline $\begin{array}{l}\text { the manager as a decision } \\
\text { maker }\end{array}$ & $\begin{array}{l}\text { - technical problems; } \\
- \text { "intrinsic" limitations in decision } \\
\text { making. }\end{array}$ & Technical Expert \\
\hline
\end{tabular}

\section{THE ANALYSIS OF WORK HABIT CHANGES}

The described analysis of manager decisional requirements is not enough for designing effective DSS. Frequently, decision support systems fail when they are introduced in organizations, even if they satisfy all the decision requirements of the managers (Keen, 1980; Ginzberg and Ariav, 1986).

This paragraph will analyze some causes of failures of DSS introduction from the perspective of changes in work habits. The introduction of a DSS changes the work habits of several people apart from the manager gaining direct benefits from the application. Those changes cause problems in DSS introduction and may lead it even to a complete failure.

One of the most important problem in the introduction of managerial DSS is the disparity between benefits for managers and additional work for other employees.

On one hand, there are great benefits for the managers who decide on the introduction of the decision support system. On the other hand, a DSS often requires that some people do additional work (for example for data entry processes), while those people are not the ones who perceive a direct benefit from the application (Grundin, 1989).

This extra work is extremely important for the success of the DSS, as it ensures the correctness of the data that form the basis of the decisional support. But employees may have a low motivation to do it well, as it is an additional work that doesn't produce direct benefits for them (Ehrlich, 1987).

The search of an appropriate solution for this problem has to be one of the central aims in designing decision support. Two classical solutions are proposed in literature: changing job description (mandatory solution) or enlarging benefits of the DSS to everyone uses it (involvement solution).

The mandatory solution is based on a top-down logic of organizational change: it supposes that organizations have to adapt to a well-designed technical system. Job description and personnel characteristics are changed in order to cope with new IT system.

The costs of this change may be very high and are mainly due to personnel qualification: new job descriptions require skills improvements, training periods, new criteria for personnel evaluations, changes in labour contracts. The costs of this solution may be justified if the introduction of the new decision support system affects the whole organizational information system, for example when the new managerial DSS is part of a new information system that involves the whole organization. (Cherns, 1980; Rowe, 1985)

Otherwise the second solution is generally to be preferred (Grudin, 1989). The involvement solution follows the logic of modifying both the system and the organization to adapt each other. 
The designer has to modify the decision support to enlarge its benefits also to other employees (apart from the manager). This means building in additional features, changing the system architecture, etc. New benefits partially change work activities, for example, with the reduction of routine tasks or the facilitation in doing the job. Even if a training period is always required, the personnel costs are generally lower than in the mandatory solution. Technical costs instead increase, because the application gets more complex to implement and more difficult to manage.

A second problem in introducing decision support regards the match between user capabilities and technical requirements of the application (Phillips, 1992). On one hand, some users (also managers) have low expertise in computer usage and are not accustomed to use complex IT tools. On the other hand decision support complexity is difficult to reduce and to hide to the end-user.

Two classical solutions to this approach regard the design of easy man-machine interfaces (changes in the system) and the planning of effectiveness training period (changes in the organization).

The design of man-machine interfaces should produce DSS which are easy to learn and to use, so as to obtain user satisfaction and prevent failures of the system due to the handicap of complexity (Alter, 1990; Keen and Scott-Morton, 1978; Rockart and DeLong, 1988).

Interface design includes also the implementation of different facilities for improving user friendly features of the system, such as possibilities for user customization (choice of colours, system driven process versus user driven process, ...), help on line, etc.

The training period is equally important for reducing the gap between user expertise and DSS capability requirements. This phase is effectively made if it is aimed not only at explaining system function but also to promote the use of the system. It has to make the users appreciate the advantages deriving from the system, in order to motivate them to use the system and to reduce the fear of the new tool.

The problems deriving from changes in work habits sometimes are objective and due to real small revolutions, but sometimes they may be only due to wrong perceptions and/or wrong images of the tool.

Users and designers often describe an IT system through metaphors (DeSanctis, Snyder and Poole, 1994) that are generally influenced by previous experiences and/or by personal attitudes and preferences. People with low expertise on computer usage may develop an unjustified fear of using new tools and so refuse to face up to and to solve the real problems. The use of design techniques based on user participation (for example prototyping) correct wrong metaphors of the system and reduce the possible fear of the users against the new technical tool (Hirschheim and Klein, 1989; Madsen, 1989).

The work-habits-changes perspective requires from the DSS designer the capability of facilitating the user in adopting the new tool. The designer has to play the role of technical facilitator, the one who modifies the tool in order to adapt it to organizational and personal characteristics (for example in designing easy man-machine interfaces), as well as the role of organizational facilitator, when he modifies the organization to adapt to the system (for example with dealing with job redesign, training the users, controlling emergent metaphors of the systems, etc) (table 3). 
Table 3. A synthesis of the analysis of work habits changes

\begin{tabular}{|c|c|c|}
\hline Key actors & Considered Constraints & Role of the designer \\
\hline $\begin{array}{l}\text { - organizational decision } \\
\text { maker } \\
\text { - non-expert users } \\
\text { - employees with no direct } \\
\text { benefits from the DSS }\end{array}$ & $\begin{array}{l}\text { additional work for data entry } \\
\text { and background activities; } \\
\text { gap between capability required } \\
\text { by the DSS and expertise of its } \\
\text { users } \\
\text { - wrong metaphors of the system }\end{array}$ & $\begin{array}{ll}\text { - } & \text { Technical Facilitator } \\
\text { - } & \text { Organizational Facilitator }\end{array}$ \\
\hline
\end{tabular}

\section{THE ANALYSIS OF POLITICAL DSS REFUSAL: A RELATIONAL APPROACH}

Some DSS introductions fail even if they're well designed according to technical perspectives as well as in relation to work organization impact. Some of the users may boycott the tools, as they are afraid of losing part of their power in the organization. In fact, the introduction of a new DSS for providing a particular user (the manager) with an enlarged amount of information and expertise might change the existing organizational power equilibrium (Markus, 1983; Grover, Lederer and Sabherwal, 1988; Scarbrough and Corbett, 1992). Those organizational actors, who are penalized by the system, will try to defend their position with several strategies, from incorrect communication of data to an attempt to make the tool fail entirely.

The effective design of a managerial DSS requires a third point of view regarding the possibility of opportunistic and strategic behavior of organizational actors (March, 1991).

This phenomenon is generally studied through two classical perspectives from organization theory: the transaction-cost perspective and the power perspective.

\subsection{The transaction costs perspective}

The transaction cost perspective describes every link between two (or more) organizational actors through the concept of economic "transaction". Four phases compose a transaction: the research of the counterpart, the negotiation of contractual conditions, the control of the exchange and the maintenance of the link (Williamson, 1975).

Organizations are designed in order to minimize the transaction cost (i.e. the sum of the costs for the four phases): the best solution is chosen among three pure organizational forms (market, hierarchy, clan) or among mixed forms (Williamson, 1979; Ouchi, 1980).

IT tools generally modify transaction costs: in this way a DSS introduction may change the best organizational form (for example from hierarchy to market).

According to the transaction cost perspective, IT tools may fail because of opportunistic behavior of (some) organizational actors: those who have not economic interest in reducing transaction cost (and in moving to a new organizational model) will not collaborate in designing the new information system and in its introduction in the organization.

The focus on economic costs only is the main limit of the transaction cost theory. This approach doesn't consider social and psychological aspects, technical constraints, interpersonal links, etc., that are as important as economic transactions in IT design. The transaction costs 
perspective application needs to be completed with the analysis of other dimension involved in organizational interaction, apart from the economic one (Ferioli and Migliarese, 1995).

\subsection{The power perspective}

A second classical organizational theory is the power perspective: with respect to the transaction cost theory, the centre of the analysis is extended from the concept of economic transaction to the larger concept of organizational power.

The power perspective analyzes how the introduction of an IT based system may modify the distribution of power among organizational actors (Keen, 1981; Newman and Noble, 1990). Those changes determine the extent to which organizational actors promote, accept or refuse the system (the rule is that everyone tries to maintain or to augment his own power).

The difference of interest in using the system might cause a conflict between the organizational actors in favor of the tools and the ones against it (Bariff and Galbraith, 1978 ). The resulting force field will determine the success or the failure of the new Information System: the difference of power will decide the game.

The power perspective foresees the use of power every time there is a difference of interest between two organizational actors (Pfeffer, 1981). This analysis of organizations is only partially true: as a matter of fact, in some cases power is exerted even without diverging interests, in other cases contrasting interests don't cause power conflicts. The predictability of organizational behavior and conflicts is the main problem of power perspective use in DSS design, when it's necessary to foresee the power reaction a new IT system may cause.

For this reason the use of the power perspective has to be coupled with a deeper analysis of the reasons that may lead to or prevent organizational conflict.

\subsection{The proposed Relational Perspective}

The two previous sections have underlined some limits in the two classical perspectives for the analysis of DSS political refusal (the transaction costs theory and the power perspective). In the following the paper proposes a third approach, based on the analysis of the network of organizational relations existing among organizational actors, that overcomes the described limits. This Relational Perspective is presented here as alternative to the two classical perspectives (and in this sense it is used in the application described in par. 5); nevertheless it could be used also together with the transaction cost theory and/or the power perspective, for completing and enriching the analysis.

The word "relation" was firstly introduced in organization theory by Elton Mayo and his Human Relations school. Even if nobody can deny the importance of this school in organization studies, the concept of relation is used here with a limited meaning: (1) only interpersonal relations are considered; (2) the analysis is centered on the organizational climate, whereas the relation remains only on the back.

Some authors (Gabarro, 1990; Granovetter, 1992; Ferioli and Migliarese, 1994) have proposed the concept of relation as the basis for organizational analysis. The relation describes the link between two organizational actors according to several dimensions (Donati, 1991): it 
may be considered as an extension of the economic transaction to include also interaction of other types (such as social links, technical interdependencies, psychological interactions, etc.) (Migliarese and Ferioli, 1995).

Examples of organizational relations are:

- an internal market mechanism, with an internal price system for regulating exchanges among organizational units (economic relation);

- interpersonal contacts (social relation);

- an IT based network linking two offices (technical relation);

- the authority link between a supervisor and his subordinates (hierarchical relation)

- the esteem of a young employee toward an old expert (psychological relation)

- etc.

In the analysis of the network of organizational relations, organizations are considered as networks composed of nodes and of relations linking the nodes.

Several criteria may be defined for the location of nodes: formal borders of organizational units, similarity in technical activity, equality in hierarchical position, similarity in professional qualification, etc. For the purposes of relational analysis, the best criterion is the relational homogeneity of nodes: this defines the nodes so that all the components of a node have the same set of relations with every other organizational actor (Baker, 1992).

The width of the nodes varies in relation to the size of the analysis (Ferioli and Migliarese, 1994). For example, if the analysis concerns a whole organization with many divisions located in several countries, a local factory may be considered a node; whereas if the analysis is limited to a shop floor the size of nodes is restricted to the individual employee.

Each node is linked to the other nodes through a set of relations. For example a subordinate may be linked to his supervisor through: (1) a hierarchical relation, (2) a psychological relation (esteem of supervisor expertise), (3) a technical relation (interdependencies in work activities), (4) a social relation (due to friendship).

The analysis of the sets of relations linking the nodes (i.e. the analysis of the network of relations) enables prediction of the behavior of each node toward the other ones: for example the previous subordinate-supervisors relations will be generally characterized by trusting and collaborative behavior and will refuse opportunistic behavior and/or conflictual use of power.

In this way, the analysis of existing network of relation explains the political reaction that a DSS introduction may cause in an organization. For example, opportunistic behavior on the part of the users and attempts to boycott the tool will be expected whenever there are conflictual relations between the managers (the nodes gaining direct benefits from the systems) and the employees who are requested to entry the data.

But, specifically in the Relational Perspective proposed when talking about nodes and relations, we are referring to a structural perspective of organizational units, nodes and relations combined with a personalistic view: when referring to nodes, the Relational Perspective implies an organizational unit and a specific employee. So the Relational Perspective combines a structural organization analysis with an individual, social and psychological perspective. Social determinism and functionalism are avoided.

The Relational Perspective requires the DSS designer to understand the existing network of relations and to prevent organizational "nodes" from engaging in opportunistic behavior and 
from disruptive power conflicts. For this goal he has to modify both the tool and the organization.

Changes in the tool could reduce the causes of conflict and restore the original power equilibrium (technical facilitation).

Changes in the organization could vary from forcing new power equilibrium (dismissal of nodes against the system) to modifying the network of relations in order to facilitate a painless conflict solution (mediating solution).

The analysis of the existing network of relations as well as the proposal of good organizational solution requires from DSS designer also political competence (Table 5).

Table 5. A synthesis of the analysis of political oppositions

\begin{tabular}{|c|c|c|}
\hline Focus & Considered Constraints & Role of the designer \\
\hline $\begin{array}{l}\text { - organizational decision } \\
\text { maker } \\
\text { - } \quad \begin{array}{l}\text { opportunistic } \\
\text { organizational actors }\end{array} \\
\text { - } \\
\text { self-interest behavior }\end{array}$ & $\begin{array}{l}\text { non collaborative/boycotting } \\
\text { behavior } \\
\text { - attempts to maintain/augment } \\
\text { individual power } \\
\text { - existing network of relations }\end{array}$ & $\begin{array}{l}\text { - Technical Facilitator } \\
\text { - Political mediator }\end{array}$ \\
\hline
\end{tabular}

\section{AN APPLICATION: THE DSS DESIGN FOR A HEALTH AGENCY}

In this section we will describe the application of the three indicated perspectives for implementing managerial DSS in an Italian public health agency. The case regards the psychological and social division of the health agency. This division provides a town of about 120,000 persons with psychological services and social work.

An expert psychologist is the manager of the division: his task is very broad and covers, for example, the technical supervision of other employees, the institutional deputation of the division, psychological consulting, planning and control of the division's activities. This psychologist is one of the four top managers of the health agency: so he's always very busy with his work.

The other psychologists and social employees of the division are organized in nine teams. Three teams deal with child patients (from 0 to 14 years old), three with adolescent patients (from 14 to 18 years old) and three with senior patients (more than 18 years old). Each group of three teams has a sector-head psychologist and each team a team-head psychologist (Fig. 2).

Moreover the division is composed of some administrative employees, working in a central office under the direction of an administrative boss.

At the beginning of 1994, the division manager asked a consulting-team (composed of the authors of this paper) for the design and the implementation of a managerial DSS.

The introduction of a managerial DSS in this psychological and social division required a complex process of organizational change and political mediation in the organization. The initial decisional user requirements were modified and complemented with other features in order to make the organization accept the new system. 


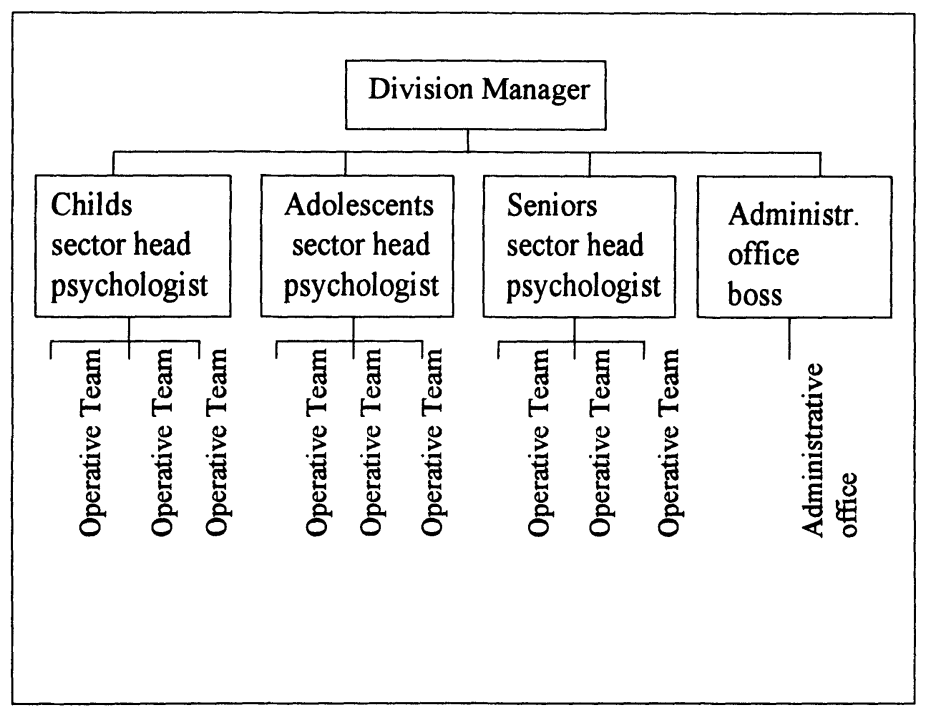

Figure 2. The social and psychological health division.

\subsection{The manager's decision support requirements}

The division manager asked for a managerial DSS for supporting his planning activities. He wanted an IT based tool providing help for decision taking in annual plan formulation as well as in three-year long plan activity. The manager needed an accurate and synthetic description of the past activities of his division (data such as: the number of patient with certain diseases, the frequency of certain psychological treatments, the correlation between external conditions and certain diseases, etc.) in order to formulate a good organizational plan for the future.

A DSS was designed, based on data collected about the teams' activities. At least once a week, each psychologist and social employee would have provided data about his own patients (diagnosis, therapy, results, etc.), through structured interfaces for computer data entry. Through the tool, the manager would have extracted the required statistical information from data collected.

Uncertainty about which data to collect was one of the main problems in this design phase: information required by the manager may vary in relation to new planning needs. Attention was paid in designing a flexible system: the possibility for new user-defined queries was introduced and the data base was built in order to be easy to modify.

When the news of the introduction of the new DSS circulated in the organization, psychologists and social employees expressed their strong opposition against the new IT system. Some causes of opposition were easy to foresee while others were less clear. For preventing system failure, the division was analyzed according to the work-habits-changes perspective and the relational perspective. 


\subsection{The work habits perspective.}

The DSS introduction would have changed the work habits of the psychological and social employees.

First, most of the psychologists and social employees did not have any expertise in computer usage. Even if the data entry interfaces were user friendly and easy to use, the DSS would have required a minimal amount of computer learning. In most employees the need for a training process caused an "a priori" refusal of the system: some employees refused to have to learn a new subject.

Second, the DSS was designed for managerial planning activities. Psychologists and social employees would have obtained no direct benefits from the system, whereas they would have taken on the data entry activity. Even if interfaces were designed in order to minimize the time required for data entry, psychologists and social employees had to modify their work organization for maintaining the data base. This caused a diffused refusal of the new DSS.

\subsection{The Relational Perspective.}

The analysis of the network of relations in the division revealed a third cause of opposition against the DSS. Four nodes were detected with the criterion of relational homogeneity:

1) the manager.

2) the administrative employees

3) the team head psychologists and a few other social employees

4) the remaining psychologists and social employees.

The relations discovered among the four nodes are complex and composed of several dimensions. In the following the paper provides only a synthetic description, sufficient for understanding the case (Figure 3 and Figure 4).

\section{Relations among node 2 and nodes $1,3,4$.}

Node 2 is linked with similar relations to all the remaining nodes.

First, there is a technical relation based on the work flow of documents from/to administrative office to/from psychological teams.

Second, there is an important social relation. Psychologists appreciate administrative employees, because they relieve psychologists from all the fastidious bureaucratic problems and duties. Administrative employees esteem psychologists and social employees, because of their professional preparation and their ability to deal with patients. The emerging social relation is characterized by a mutual liking that enables a good work collaboration. 


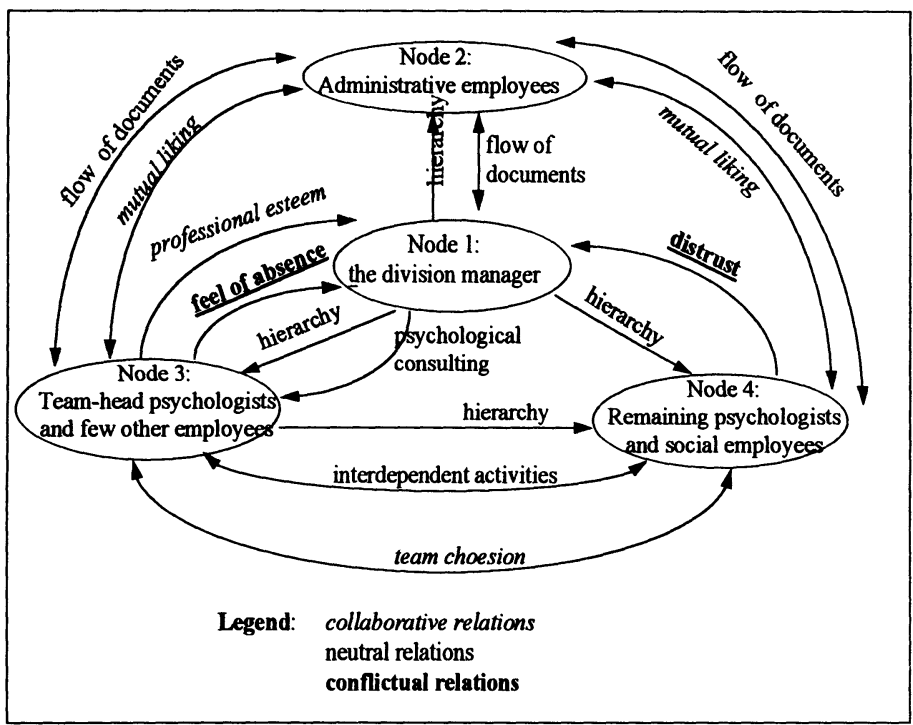

Figure 3. The network of relations in the social and psychological division.

\section{Relations between node 1 and node 3.}

The link between node 1 and node 3 is based on four main relations:

(a) hierarchical relation: node 1 is the supervisor of the components of node 3;

(b) technical relation: the division manager (node 1) gives psychological consulting to team head psychologists (node 3);

(c) psychological relation of esteem: the psychologists and social employees of node 3 recognize the professional capability of the division manager and his psychological expertise.

(d) psychological relation of absence: the division manager is very busy also with his institutional task (he is one of the top managers of the health agency). This causes frequent small conflicts with head team psychologists, as they perceive him as far from the division.

The resulting relation may be defined "neutral": there is a mutual professional trust that enables an effective work collaboration (relations "b" and "c"). Nevertheless, interpersonal relations remain quite cold, because of relation "d".

\section{Relations between node 1 and node 4.}

The relation between node 1 and node 4 is based (i) on the hierarchical authority of the manager (hierarchical relation) and (ii) of a relation of mistrust of node 4 toward node 1 .

Because of work load problems, the division manager gives direct psychological consulting only to the team head psychologists: the remaining psychologists and social employees have few opportunities for working together with him. Consequently members of node 4 don't 
appreciate the professional capability of the division manager: they see him only as a hierarchical boss.

Moreover the feel of division manager absence - see previous relation " $\mathrm{d}$ " between node 1 and node 3 - is perceived also by components of node 4 .

In the resulting relation, work collaboration is very difficult and many psychologists mistrust the manager.

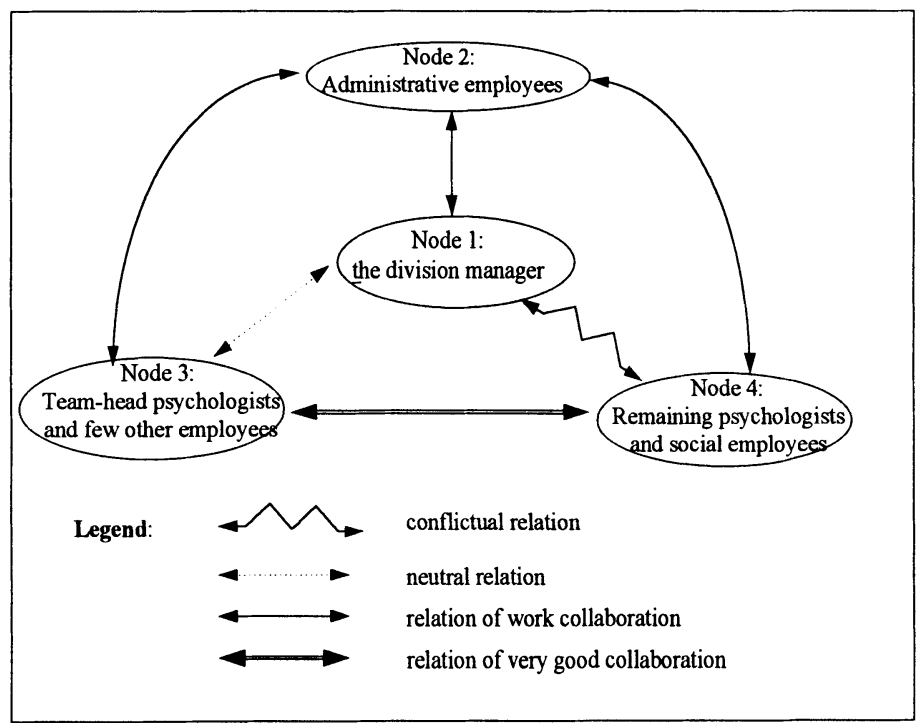

Figure 4. A synthesis of the network of relations in the social and psychological division.

\section{Relations between node 3 and node 4.}

The link between node 3 and node 4 is based on:

(a) hierarchical supervision of members of node 3 toward components of node 4

(b) technical relations. Between the activities of the two nodes there are complex interdependencies as they work together in the teams caring for patients.

(c) social relations: the team based organization and the particular task (the care of social and psychological disease) has developed a strong cohesion among team members. Interpersonal relations are characterized by trust, commitment to mutual help, friendship. These teams may be correctly defined as "clans" (Ouchi, 1980).

The resulting relation is very warm and it enables a strong work collaboration.

\section{Conclusions on the network of relations analysis}

The managerial DSS was perceived as a relational instrument. Existing relations influenced the "political" judgment to its introduction in the organization. 
Psychologists and social employees of node 4 were particularly against the DSS. Because of the existing relation between node 4 and node 1 (Fig. 4), they saw the new IT tool as an instrument of control of their activity imposed by the manager.

The opposition of other psychologists and employees (belonging to node 3) was less strong, and limited to work habits change reasons. Nevertheless the warm relation linking node 3 to node 4 prevent psychologists belonging to node 3 from taking sides in favor of the DSS.

\subsection{Case Solution.}

The design and system implementation strategies were modified for solving the three problems which had emerged as causing the initial refusal of the DSS:

PROBLEM 1: psychologists and social employees were afraid of the DSS because of their low expertise in computer usage;

PROBLEM 2: psychologists and social employees had to change their work habits without obtaining any direct benefits from the DSS;

PROBLEM 3: the components of node 4 perceived the DSS only as a tool for hierarchical control.

Four solutions were adopted (Table 6).

First, the design team adopted design techniques based on user participation: several meetings with employees (belonging both to node 3 and to node 4) took place for explaining the future functions of the DSS and for understanding their oppositions. This reduced the fear of an unknown system that caused an initial "a priori" refusal of the system (PROBLEM 1).

Second, the data base of the DSS was modified. Some suggestions of the employees belonging to node 4 were accepted, in order to eliminate the fear of a system designed only for controlling their activity (PROBLEM 3).

Third, the functions of the DSS were changed: a lot of new features were added so to make the system useful to all the psychologists and social employees. The DSS was transformed from a statistical tool to an IT based psychological chart. Everybody (and not only the manager) obtained benefits from the new system (PROBLEM 2). Moreover the new DSS was no longer seen as a tool for hierarchical control, but as an instrument useful for all the employees (PROBLEM 3)

Fourth, also the administrative employees were trained in using the system. Administrative employees were expert in computer usage so the training for using the DSS was very cheap. The benefits instead were great: thanks to their collaborative relations with psychologists and social employees, administrative employees provided an important technical help to psychologists and social employees in using the DSS and in assuring a continuous training on the field (PROBLEM 2). 
Table 6. The solution for the DSS introduction in the social and psychological health division

\begin{tabular}{|c|c|}
\hline Discovered Problems & Adopted Solutions \\
\hline $\begin{array}{l}\text { 1. poor expertise of psychologists and social } \\
\text { employees in using PC systems that caused an "a } \\
\text { priori" refusal }\end{array}$ & $\begin{array}{l}\text { - } \text { several design meetings with user } \\
\text { participation } \\
\text { - administrative employees' support }\end{array}$ \\
\hline $\begin{array}{l}\text { 2. psychologists and social employees didn't } \\
\text { obtain direct benefits in using the system }\end{array}$ & $\begin{array}{l}\text { the DSS was changed from statistical tool to } \\
\text { IT based psychological chart }\end{array}$ \\
\hline $\begin{array}{l}\text { 3. some social employees feared of more } \\
\text { hierarchical control }\end{array}$ & $\begin{array}{l}\text { - the DSS data base was modified and several } \\
\text { social employees suggests were introduced. } \\
\text { - the DSS was changed from statistical tool to } \\
\text { IT based psychological chart }\end{array}$ \\
\hline
\end{tabular}

The resulting tool was quite different from the one initially designed. Software implementation was more complicated and more expensive, but the design team solved the emergent problems and the tool was successfully introduced in the organization.

Moreover the DSS introduction changed the existing network of relations. The relations between node 2 (the administrative employees) and node 3 (the team head psychologists) and the ones between node 2 and node 4 (the remaining psychologists and social employees) were enriched by the continuos training in the field that administrative employees provided to psychologists and social employees concerning DSS use (Figure 5).

The resulting relations have become strongly oriented to work collaboration (Figure 6).

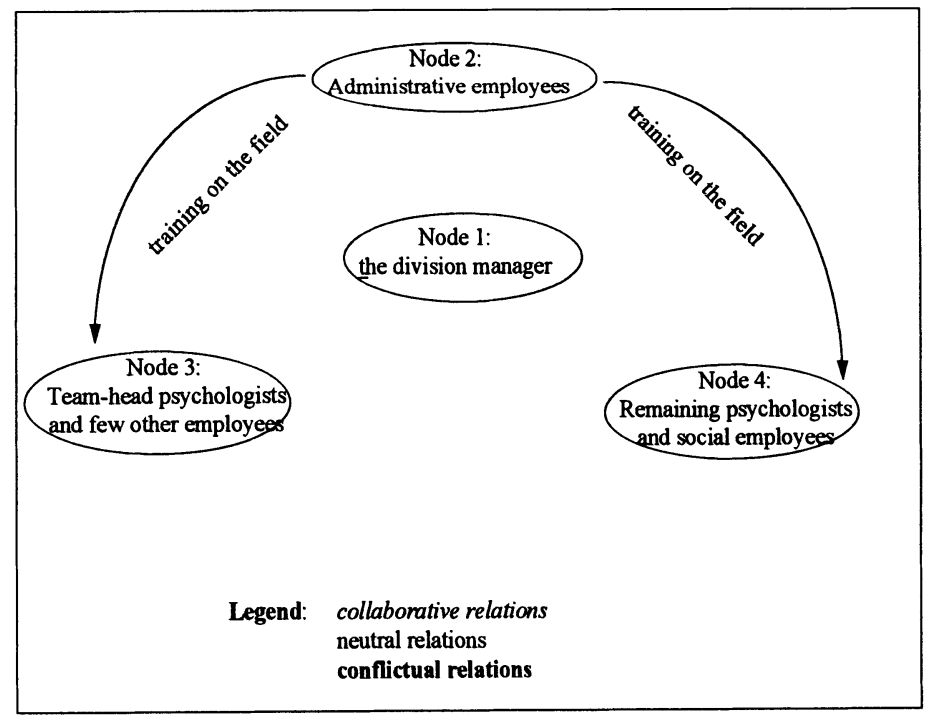

Figure 5. The new relations due to the DSS introduction. 


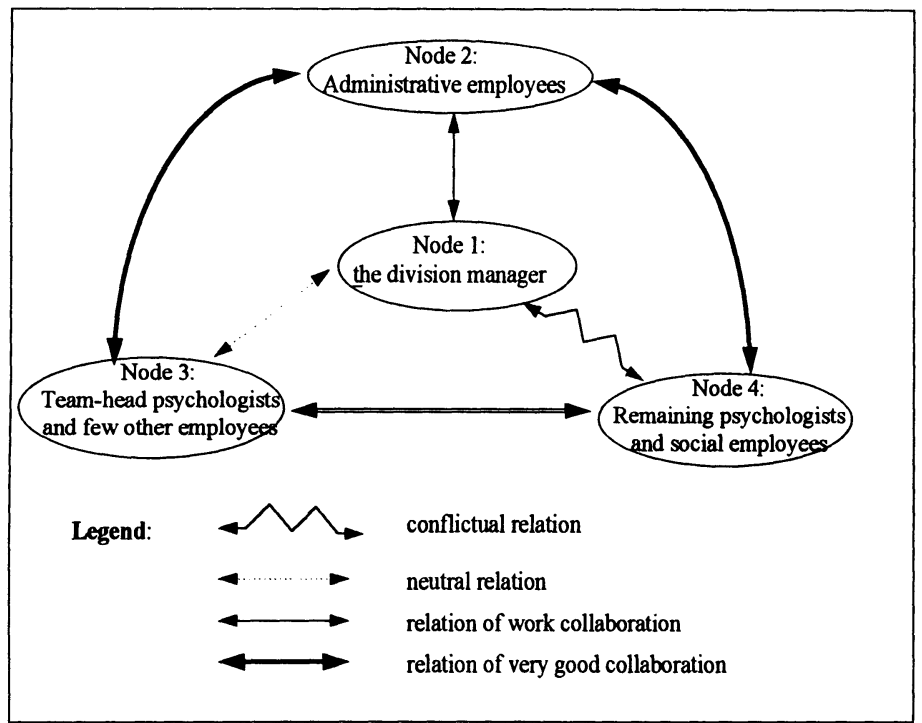

Figure 6. A synthesis of the network of relations in the social and psychological division, after the DSS introduction.

\section{CONCLUSIONS AND REMARKS FOR FUTURE RESEARCH}

The introduction of a new DSS in an organization is similar to the introduction of every new technical system in a socio-technical environment. Apart from technical problems, social and organizational aspects are also important for deciding the success or the failure of the tool.

The design approach proposed in this paper underlines three aspects as relevant for preventing DSS from failure:

- the analysis of the decision needs of the manager

- the analysis of changes in users' work habits caused by the tool

- the analysis of (possible) political opposition against the DSS.

This approach has been tested on a particular class of DSS: those requiring a continuos data entry activity by some employees, who are different from the manager and don't receive direct benefits from the tool.

Future researches should be conducted to provide further validation of the proposed approach and for its extension also to other kind of DSS. 
The paper has also proposed a new method of analysis, based on the study of the network of organizational relations. This relational method provides the basis for the analysis of the political problems caused by the introduction of DSS in organizations.

The relational analysis of organizations is the subject of research that is now being conducted about the use of innovative IT applications in organizations and in new models of organizations (for example: Ferioli and Migliarese, 1994; Ferioli and Migliarese, 1995).

Some real applications (such as the health agency described above) have proved the validity of the relational analysis method: for this reason the paper indicates that relational analysis is a promising area for future research on DSS design and introduction in organizations.

\section{REFERENCES}

Alter, S.L. (1990) Decision Support Systems: Current Practice and Continuing Challenges, Addison-Wesley, Reading, MA.

Angehrn, A.A. and Jelassi, T. (1994) DSS research and practice in perspective. Decision Support Systems, 12, 267-275.

Argyris, C. (1982) Reasoning, Learning and Action. Jossey-Bass, San Francisco

Baker, W.E. (1992) The network organization in theory and practice. In Networks and Organizations, (ed. Nohria N. and Eccles R.G.), Harvard Business School Press

Bariff, M. and Ginzberg, M. (1982) MIS and the behavioural sciences. Data Base, 13, 1, 19-26

Bariff, M.L. and Galbraith, J.R. (1978) Intraorganisational Power Considerations for designing Information Systems. Accounting, Organizations and Society, 3, 25-27.

Bell, P.C. (1992) Decision Support Systems: Past, Present and Prospects. Journal of Decision Systems, 1, 2-3, 127-137.

Briefs U., Ciborra, C. and Schneider L. eds. (1984) System Design for, with and by the Users. North-Holland, Amsterdam

Cherns, A.B. (1980) Speculations on social effects of new microelectronics technology. PC/Computing, September 1988, 21.

Ciborra, C. (1993) Teams, Markets and Systems. Cambridge University Press, Cambridge.

Ciborra, C., Migliarese, P. and Romano P. (1984) A methodological inquiry of Organizational Noise in Socio-technical Systems, Human Relations, 37, 8, 565-88.

Davies, W.S. (1992) Operating Systems, A Systematic View. Benjamin Cummings, New York.

DeMarco, T. (1979) Structured Analysis and System Specification. Yourdon Press, New York.

DeSanctis, G., Snyder, J.R. and Poole, M.S. (1994) The meaning of the interface. Decision Support Systems, 11, 319-335.

Donati, P.P. (1991) Teoria relazionale della società, Franco Angeli, Milano.

Ehrlich, S.F. (1987) Strategies for encouraging successful adoption of office communication systems. ACM Transactions on Office Information Systems, 5, 340-357.

Ferioli, C. and Migliarese P. (1995) Opportunities and drawbacks of information technology in the emerging forms of organization. In Proceedings of the Third European Conference on Information Systems (ed. Doukidis G., Galliers R., Jelassi T., Krcmar H. and Land F). Athens. 
Ferioli, C. and Migliarese P.(1994) The role of IT and GDSS in internal network organizations. In Proceedings of IFIP WG 8.3 Working Conference "Decision Support in Organisational Transformation (ed. B. Mayon-White, S. Ayestaràn and P. Humphreys), San Sebastian.

Gabarro, J.J.(1990) The Development of Working Relationships. In Intellectual teamwork, (ed. J.Galegher, R.E.Kraut and C.Egido), Lawrence Erlbaum Associates, New Jersey.

Gallupe, R.B., Bastianutti, L.M., Cooper, W.H. (1991) Unblocking brainstorms. Journal of Applied Psychology, 76.

Gardner, A.L., Paul, R. and Patel, N.V. (1995) Moving beyond the fixed point theorem with tailorable information systems. In Proceedings of the Third European Conference on Information Systems (ed. G. Doukidis, R. Galilee's, T.Jelassi, H.Krcmar and F.Land).

George, J.F, Nunamaker Jr, J.F. and Valacich, J.S. (1992) ODSS Information technology for organizational change. Decision Support Systems, 8, 307-315

Ginzberg, M.J, and Ariav, G. (1986) Methodologies for DSS Analysis and Design: a Contingency Approach to their Application. In Proceedings of the 7th International Conference on Information Systems, San Diego, CA.

Gorry, A. and Morton, S. (1971) A Framework For Management Information Systems, Sloan Management Review, 13, 1, 55-70.

Granovetter, M.(1992) Problems of Explanation in Economic Sociology. In Networks and Organizations, (ed. Nohria N. and Eccles R.G.), Harvard Business School Press.

Grover, V., Lederer, A.L. and Sabherwal R. (1988) Recognizing the politics of MIS. Information and Management, 14, 3, 145-156.

Grudin, J. (1989) Why groupware applications fail: problems in design and evaluation. Office Technology and People, 4, 3, 245-264.

Heiner, R. (1983) The origin of predictable behavior, American Economic Review, 73, 560-95.

Hewitt, C. and De Jong, P. (1984) Open systems. in On Conceptual Modeling (ed. M.L. Brodie, J. Mylopulos and J.W.Schmidt) Springer, New York.

Hirschheim, R. and Klein, H.K. (1989) Four Paradigms of Information Systems Development. Communications of the ACM, 32, 10, 1199-1216.

Ives, B. and Olson M.H. (1984) User involvement and MIS success: a review of research. Management Science, 30, 5, 586-603.

Keen, P.G.W. (1981) Information Systems and Organizational Change. Communications of the $A C M, 24,24-33$.

Keen, P.G.W. (1980) Adaptive Design For Decision Support Systems. Data Base, 12, 1-2, 1525

Keen, P.G.W. and Scott-Morton, M.S. (1978) Decision Support Systems: An Organizational Perspective, Reading, MA.

Land, F. (1995) The new alchemist: or how to transmute base organizations into corporations of gleaming gold, in Proceedings of the Third European Conference on Information Systems (ed. G. Doukidis, R. Galliers, T.Jelassi, H.Krcmar and F.Land).

Lee, R.M., McCosh, A.M. and Migliarese P., eds.(1988) Organizational decision support systems, North-Holland.

Madsen, M. (1989) Breakthrough by breakdown. In Information Systems Development for Human Progress in Organizations (ed. H.Klein and K.Kumar), North-Holland, Amsterdam March, J. (1991) How decisions happen in Organizations. Human-Computer Interaction. 
Markus, M.L. (1983) Power, Politics and MIS Implementation. Communications of the ACM, 26, 6, 430-444.

McMenamin, S. and Palmer, J (1984) Essential Systems Analysis. Yourdon Press, New York.

Migliarese, P. (1992) Sistemi di supporto per i processi decisionali. In Progettare e gestire l'impresa innovativa (ed. R.Filippini, G.Pagliarani, G.Petroni), ETAS Libri, Milano

Migliarese, P., Paolucci, E. (1995) Improved communications and collaborations among tasks induced by Groupware. Decision Support System Journal, 14, 237-250.

Migliarese, P. and Ferioli, C. (1995) Strumenti organizzativi ed informatici di collaborazione nellimpresa innovativa, in proceedings of the workshop AiIG: Organizzazione, risorse umane e processi innovativi nello sviluppo del sistema delle imprese, Torino, Italy.

Mumford, E. (1979) Computer Systems In Work Design: The ETHICS method, Associated Business Press.

Mumford, E. (1991) Decision Making And The Organizational Environment: Today's Problems And Tomorrow's Needs. In Environment for Supporting Decision Processes (ed. H.G.Sol and J.Vecsenji), North-Holland.

Newman, M. and Noble, F. (1990) User Involvement as an Interaction Process: a Case Study. Information Systems Research, 1, 89-113.

Norman, D.A. (1983) Some observations on mental models. in Mental Models (ed. D. Gentner and A.L. Stevens) Lawrence Erlbaum, Hillsdale, N.Y.

Nunamaker Jr, J.F., Vogel, D. and Konsynski (1989) Interaction of Task and Technology to Support Large Groups. Decision Support Systems, 5, 2, 139-152.

Ouchi, W.G. (1980) Markets, Bureaucracies, and Clans. Administrative Science Quarterly, 25.

Pfeffer, J. (1981) Power in organizations. Ballinger, Cambridge, MA.

Phillips, L. (1992) Gaining Corporate Commitment to Change. In Executive Information Systems and Decision Support (ed. C.Holtman), Chapman \& Hall.

Piaget, J. (1974) Understanding Causality. Norton, New York

Polany, M. (1966) The Tacit Dimension. Doubleday, Garden City-N.Y.

Poole, M.S., DeSanctis, G. (1992), Microlevel structuraction in computer supported group decision making, Human Communication Research. 19.

Radermacher, F.J. (1994) Decision support systems: Scope and potential. Decision Support Systems, 12, 257-265.

Rockard, J.F. (1979) Chief Executives Define Their Own Data Needs. Harvard Business Review, 57, 2, 81-93.

Rockard, J.F. and DeLong D.W. (1988) Executive Support Systems, Dow-Jones, Irwin, Homewood, IL.

Rosenberg, N. (1982) Inside the Black Box: Technology and Economics. Cambridge University Press, Cambridge.

Rowe, C.J. (1985) Identifying causes of failure: a case study in computerized stock control. and Information Technology, 4, 63-72.

Scarbrough, H. and Corbett, J.M. (1992) Technology and organization. Power, meaning and design. Routledge, London

Simon, H.A. (1976) Administrative Behavior. The Free Press, New York

Sternberg, R.J. and Wagner R.K. eds. (1986) Practical Intelligence. Cambridge University Press, Cambridge.

Thompson, J.D (1967) Organizations in actions. McGraw-Hill.

Weick, K.E. (1979) The Social Psychology of Organizing. Random House, New York. 
Whitaker, R. (1994) GDSS' Formative Fundaments: An Interpretive Analysis. CSCW: An International Journal, 2, 4, 241-262

Williamson, O.E. (1975) Markets and Hierarchies: Analysis and Antitrust Implications, Free Press, New York.

Williamson, O.E. (1979) Transaction-Cost Economics: The Governance of Contractual Relations, Journal of Law and Economics, 22.

\section{BIOGRAPHY}

Claudio Ferioli participates in a number of research projects about the emergence of new organizational models and the role played by information technologies in implementing organizational changes. He collaborates with public health organizations on management consultancy and software implementation. $\mathrm{He}$ is an assistant in the class of Economics and Company Organizations and of Organizational Systems at the Politecnico of Milan.

Piero Migliarese is a full Professor of Business Economics and Organizational Systems. He teaches courses at University of Calabria - Italy and at Politecnico of Milano-Italy. He is a member of IFIP Working Group 8.3 on Decision Support Systems. His research interests are regarding innovative organizational models, information systems, group support systems. At present he proposed conceptual models regarding coordination and cooperation supports coming from Information Technologies. He has authored various papers on these subjects at national and international levels. 